\title{
Carbon Tax and Renewable Energy Diffusion in the Deregulated Texas Electricity Market: An Agent-Based Analysis
}

\author{
Joshua D. Halperin, I-Tsung Tsai \\ Department of Engineering Systems and Management, Masdar Institute of Science and Technology, Abu Dhabi, \\ United Arab Emirates \\ Email: jhalperin@masdar.ac.ae, itsai@masdar.ac.ae
}

Received February 2015

\begin{abstract}
In the United States, emission regulations are enacted at a state level; individual states are allowed to define what methods they will use to mitigate their carbon emissions. The consequence of this is especially interesting in the state of Texas where new legislation has created a "deregulated" electricity market in which end-users are capable of choosing their electricity provider and subsequently the type of electricity they wish to consume (generated by fossil fuels or renewable sources). In this paper we analyze the effects of carbon tax on the development of renewable generation capacity at the utility level while taking into account expected adoption of rooftop PV systems by individual consumers using agent based modeling techniques. Monte Carlo simulations show carbon abatement trends and proffer updated renewable portfolio standards at various levels of likelihood.
\end{abstract}

\section{Keywords}

Deregulated Electricity Market, Rebewable Adoption, Agent-Based Modeling, Monte Carlo Simulation

\section{Introduction}

Climate change represents one of the largest challenges facing our planet worldwide. Increasing greenhouse gas (GHG) emissions from the combustion of fossil fuels from the electricity sector are one of the major sources of anthropogenic emissions. Effective policies to reduce GHG emissions from the electricity sector are therefore critical in the reduction of emissions.

In the state of Texas, electricity services were regulated by the state-run Public Utility Committee of Texas (PUCT) during the 1990s. Each geographical market had only one state-run electricity provider and the rates were set and monitored by PUCT. The electricity provider handled the entire power delivery process: generation, transmission and distribution, and retail sales. The supply of power under such regulatory scheme was reliable but inefficient market wise as there was no choice for the customer under the electricity monopoly [1]. In 1999, the state senate passed Senate Bill 7 (SB7) restructuring the Texas electric industry to allow retail competition 
by January 2002, paving the way for a deregulated market. Under SB7, all utility companies must dissolve into:

1) The power generation company (PGC): the entity that owns and operates power generation facilities and then sells its electricity into the deregulated market;

2) The transmission and distribution company (TDSP): the entity that owns and operates the wires and power transmission infrastructure; and

3) The retail electric provider (REP): the entity that purchases the power from the PGC and sells it to the end-use customer. They are explicitly forbidden from owning PGCs.

These three could remain under the same ownership but the power generation and retail sections must be open to market competition. The electricity demand on the grid is monitored and managed by the Electric Reliability Council of Texas (ERCOT) employing an independent system operator (ISO) to ensure electricity is delivered efficiently/fairly and thereby preventing load imbalances and subsequent swings in spot prices. This organization also acts as a watchdog over the market prices ensuring fair trade [2].

In portions of Texas that have been deregulated (currently approximately $75 \%$ of the state), the PGCs can use any fuel sources (nuclear, coal, natural gas, renewables, etc.) to generate power. Once the power is generated it is sent through power lines that belong to the TDSP. Regardless of the REP chosen by the customer, the transmission and distribution is still provided by the local TDSP. As the middle-men between the end-user customers and the PGCs, the REPs purchase wholesale electricity from the PGCs and then offer the electricity to their customers. They structure deals with the PGC for electricity production with terms unknown to the public. In negotiating contractual agreements on the wholesale electricity, the REPs have the ability to buy from providers who supply from different fuel sources including renewable electricity [3]. It is at the REP stage where the market is currently seeing an explosion in the availability of renewable electricity options.

The major incentive for the deregulated market is to allow the customers choose their REP as well as sell electricity back to the grid if they opt to do so. When a customer decides on generating and selling their own renewable power, they may sell their excess power generated to the REP from which they buy electricity, but the REPs are not required to purchase the power. Under SB7, the PUCT continues to oversee the entire electricity market as well as the municipal and cooperative-owned utilities that were not affected by the law. Additionally, SB7 mandates environmental protocols like setting up a renewable portfolio standard (RPS) and mandating that half of all new capacity must be natural gas-fired (as opposed to the more traditional coal) [4].

The RPS mandated that all utilities in the state must produce at least 2,000 MW of renewable energy (solar, wind, biomass, tidal, hydroelectric, geothermal, or landfill gas) by 2009. In 2005, the installed renewable capacity was past the 2009 goal and in the State Senate Bill 20 (SB20) an updated goal of 5,880 MW (of which at least 500 must be from non-wind resources) was set for 2015 and a further goal of 10,000 MW was set for 2025 [5]. Meanwhile, the RPS allowed for the creation of a Renewable Energy Credit (REC) trading program that could be used to help meet the renewable energy capacity goals of the RPS. This program, mandated into action until at least 2019, allowed utilities to buy and trade RECs to meet their company's RE capacity goals if, for whatever reason they did not want to install their own RE capacity directly. The RECs take the burden of power delivery off of the RE buyer and thereby create additional RE demand. For market safety, the entire REC market is monitored and controlled by ERCOT. Penalties for noncompliance with the RPS are overseen and handled by the Public Utility Commission of Texas. If necessary, PUCT can cap the REC price or suspend trading [5]. Once electricity leaves the PGCs and enters the TDSP portion (the grid), it is impossible to distinguish between electricity from different generation sources. For that reason, the RECs permit the tracking of the non-power attributes that renewable energy provides (carbon reduction, sense of environmental protection, etc.).

At the end of 2008 the Texas State Energy Conservation Office commissioned the University of Texas at Austin to analyze the performance of the REC trading system. It was concluded that the incredible achievements of the RPS in instigating new capacity created fluctuations in the REC market. The excess renewable energy capacity coupled with the small voluntary market for RECs lead to the collapse of the REC price. Additionally, because of legislative oversight, electricity generation was also outpacing transmission capacity, creating a situation where suppliers could collect funds for generating wind energy without actually being connected to the grid [6]. To move forward effectively, realistic carbon reduction policy has to be identified. This paper thus analyzes the effects of carbon taxes on the installment of renewable capacity in the deregulated Texas electricity market.

\section{The Model}

To analyze the Texas electricity market, we develop a nimble model that combines both an agent-based frame- 
work which characterizes adoptions of renewable power among individual consumers with a decision tree that characterizes the capacity building and electricity purchasing decisions made by energy consumers. We code the two sub-models on the same program to perform an integrated analysis on the diffusion of power generation profiles and the evolution of electricity Because of the high level of detail in the model, different functions are broken up into both functional groups to simplify calculations and into separate locations for a visually manageable and well-defined format. The primary division is by active object class, of which there are five in the model. The first active object class is entitled "Main." This is where the central calculations of the program take place. The largest and most important is that of pricing the different electricity offerings to the agents. The "Main" class also calculates the carbon abatement from each policy decision and updates the stock of carbon abated accordingly. Lastly, a key function of the "Main" class is writing the simulation results to the correct excel files. The remaining four active classes correspond to the four agents in the model: the power generating company, the industrial sector, the commercial sector, and the residential end-user.

\subsection{Consumer}

According to the Annual Energy Outlook (AEO) 2010, in 2008, residential electricity demand was larger than any of the other sales sectors and made up 111.07 billion kWh out of a total 285.35 billion kWh sold [7]. Utilizing data from the Electric Power Industry Emission Estimates contained within the State Electricity Profile [8], the generation of this electricity emitted 79 million metric tons of carbon dioxide in 2008 alone-an amount that is enough to be \#11 in the nation behind Alabama—82.9 million metric tons_-and in front of Michigan—77.086 metric tons. Under the current market structure in Texas, consumers are able to choose their main electricity source and making their own decisions as to the type and quantity of electricity to buy. Since these purchasing decisions are typically made on a household, we model the residential sector by 1000 representative households to achieve appropriate trade-off between resolution and model speed. Population forecasts were used from the reference scenarios generated at the Texas State Data Center and the model was initialized with 8,322,257 households in 2010, representing roughly 8,322 households per agent [9]. We use total population forecast produced by the University of Texas at San Antonio and assume that the number of households grows at a similar percentage.

Since income level affects purchasing decision, we use income distribution data generated from surveys taken between 2005 and 2009 in Texas by the United States Census Bureau to assign income to individual households in the model. In the absence of state-specific data on correlations between electricity usage and income, it is assumed that average data for households in the United States is the same for the Texas households. As a result, we use the 2005 EIA Residential Energy Consumption Surveys (RECs) data to delineate the relationship between electricity consumption and household income. Our model also analyze the willingness of a consumer to switch to purchasing renewable energy even if the cost is greater than that of fossil fuel-based electricity. In 2008, the National Renewable Energy Laboratory published the Green Power Marketing Report in which they summarize consumer participation rates in utility green pricing tables [10]. Accordingly, this model utilizes the trend established in the NREL document to characterize the "Green Conscious" population as shown in Figure 1. Since green consumers are defined simply as those willing to pay more for electricity obtained from renewable sources, our analysis assumes that a green consumer is willing to pay up to $15 \%$ more for certified renewable energy than for fossil fuels.

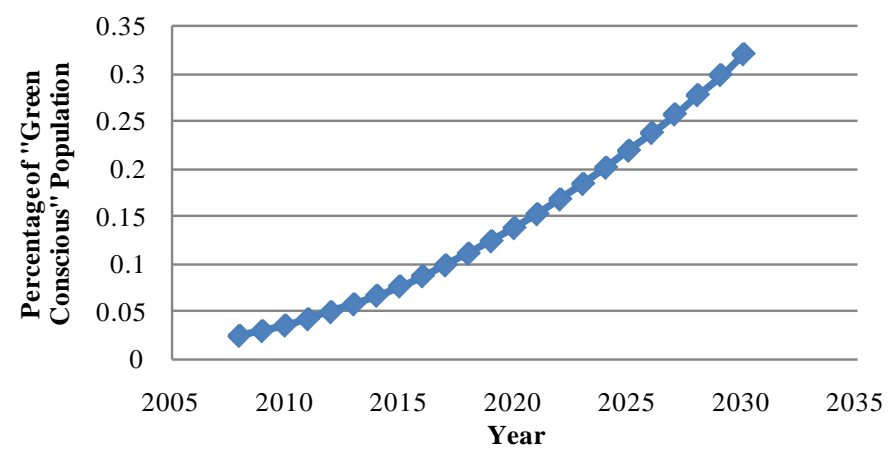

Figure 1. "Green conscious” consumers by year [10]. 
Since not every household in Texas is willing and/or capable to install PV panels on their houses, a willingness to build parameter was created and assigned to each consumer. Uniformly distributed among the population (and new agents when they are created from population increases) on the bounds $[0,1]$ with 0 representing an individual completely unwilling to build PV, the cutoff for actual willingness to build is therefore those households who have a parameter value over a certain threshold value-essentially the percentage of the market installing rooftop photovoltaics. The threshold of willingness to build in the market is set as the business as usual values market penetration values identified by a 2007 NREL report [11] with linear extrapolations up until 2030 (Figure 2). To make these values applicable to this research, it is assumed that the national average of market penetration holds for Texas and that on average all houses have an equal rooftop area.

Agent-based modeling is used to assist in modeling the decision-making aspect in the electricity industry. For the residential sector, a decision tree is devised to analyze household behavior change (Figure 3). Upon entering the statechart, an agent is considered a "PotentialEnergyUser." These are the customers who can choose their

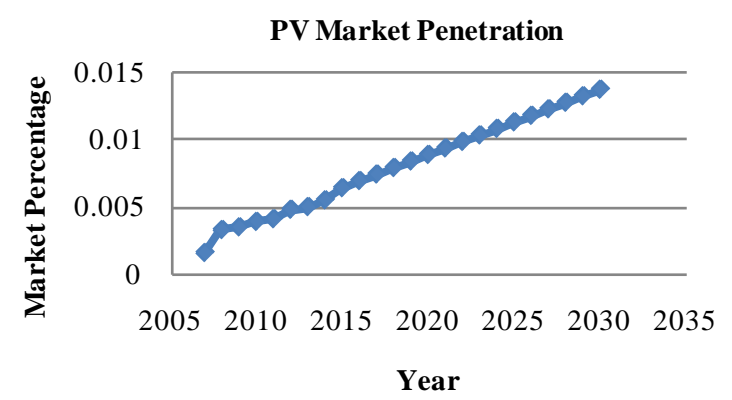

Figure 2. Rooftop PV Market Penetration NREL forecasts extrapolated until 2030 [11].

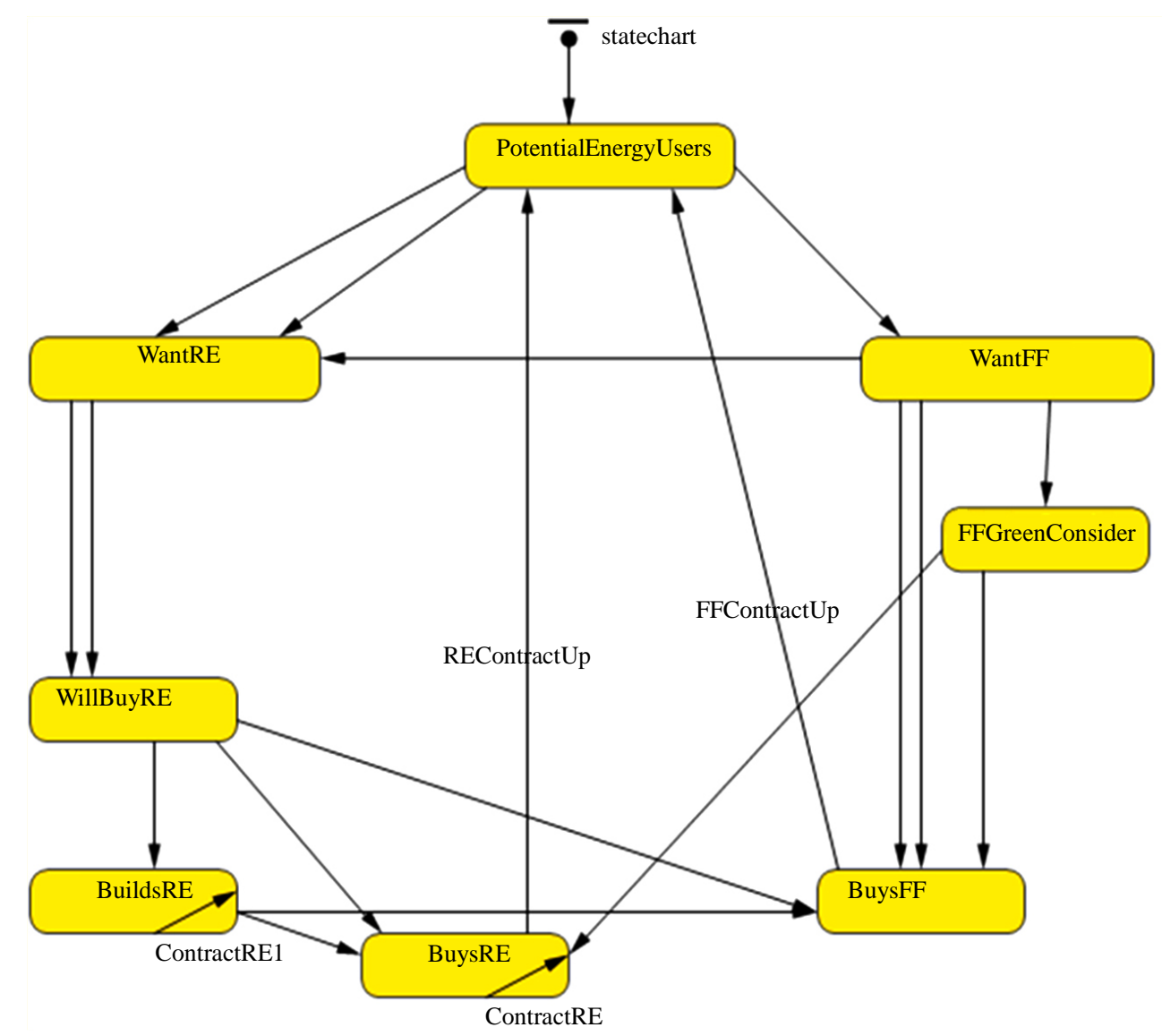

Figure 3. Consumer decision tree. 
electricity usage makeup—either fossil fuels (FF) or renewable energy (RE)—-from their Retail Electricity Provider (REPs). Initially, this decision is made strictly with financial rationale and the willingness to build. If the retail price of FF electricity is greater than that of Re electricity, the agent will purchase renewable power. However, some agents may want to build PV even if the retail RE is more expensive than standard retail electricity. For this reason, a pathway exists for a user to move to build electricity on their property and then purchase the remainder of the electricity from FF sources at FF prices. Once agents decide they will buy renewable energy, they must decide whether or not to build PV. If they are willing to buy RE and not willing to build the solar panels or if they simply cannot afford them, they will transition into the "BuysRE" state where they will purchase their electricity directly from the REP. If they choose to build PV, they will build the difference between their budget for electricity and the amount they are currently spending to fulfill their electricity needs (with the cheaper of either RE or FF).

It is assumed that all installations take place within a year and therefore the following year the agent will need to purchase less electricity than in the previous year as their PV will be providing some power. To simplify the model, all rooftop PV units are assumed to have a constant efficiency throughout the course of the model. After a consumer decides which type of electricity to purchase, they are either in the state "BuysRE" or "BuysFF." As is standard in the Texas electricity market, contracts are valid for varying amounts of time but typically lock prices into 6, 12, or 18-month periods. Our analysis assumes every household opts for a 12-month contract, during which time they are locked into the initial price at the time of contract purchase and after which time they return to being "PotentialEnergyUsers" and can again begin their choice for either RE or FF based on market conditions.

\subsection{Industry}

According to the AEO2010, in 2008 industrial electricity demand was the third largest sales sector in Texas and accounted for 83.06 billion kWh out of a total 285.35 billion kWh sold [7]. Utilizing data from the Electric Power Industry Emission Estimates contained within the State Electricity Profile, the generation of this electricity emitted over 60 million metric tons of carbon dioxide into the atmosphere in 2008 alone. Because appropriate information to model individual companies is unavailable, the model creates one representative industrial user which represents the collective of industries in Texas. The model uses the industry energy usage forecasts from 2010 through 2030 as provided in the Annual Energy Outlook [7].

\subsection{Commercial}

According to the AEO2010, in 2008 commercial electricity demand was the second largest sales sector in Texas and accounted for 91.2 billion kWh out of a total 285.35 billion kWh sold. [7] Again, utilizing data from the Electric Power Industry Emission Estimates contained within the State Electricity Profile, the generation of this electricity emitted over 66.5 million metric tons of carbon dioxide into the atmosphere in 2008 alone. This commercial agent is very similar to the industrial user. Since data is available only at a low resolution, individual decision trees are not valid in this iteration of the model. Therefore, the representative commercial entity is assumed to have only a choice between buying RE or FF from the RE power and is motivated primarily by profit concerns. The energy needs of the commercial entity are assumed to be consistent with the commercial forecasts in the reference case of the Annual Energy Outlook [7].

\subsection{REP}

The Retail Electricity Provider is the intermediary between the power generation and the consumers. In this model, rather than give the REP its own active class division, the actions of the REP are merely simulated in the coding of the "Main" class. It is assumed that all electricity orders are aggregated by the REP and that all deliveries are made to the consumers without any delay. While this is a somewhat unrealistic, it simplifies calculations and essentially removes the need for day-ahead markets. Based on the sales, the REP sets the retail electricity prices for both fossil fuels and renewable energy with an assumed profit margin added on behalf of the REP.

\subsection{PGC}

The Power Generating Companies (PGC) are the large-scale energy providers who provide electricity by a 
number of methods. According to the AEO, there are at least 32 broadly-defined generation types including many variations of coal plants, oil/gas facilities, carbonate fuel cells, nuclear and conventional renewable energy facilities. For the purposes of this study, the PGC is viewed as a representative user who provides electricity based on market demand. Since PGCs are the major electricity suppliers in Texas, they are the point source of carbon dioxide emissions in the electricity pathway. All carbon calculations in the model come from the generation at this level and are based upon the information held in the State Electricity Profiles. In 2008, Texas PGCs generated 345,381,850 MWh from non-renewable sources and in the process emitted 252,055,000 metric tons of carbon dioxide [12] for an average of 0.7287 tons $\mathrm{CO}_{2} / \mathrm{MWh}$ produced. However, the PGCs can also install RE to fill consumer demand. In reality, the gains of wind power in the deregulated Texas market have primarily come from the installation of large scale wind at the PGC level. Primarily, decisions have been based upon resource availability and profit margins. To simplify our analysis, the PGC is restricted to build only wind or solar power as, historically, these have been the two main beneficiaries of the RPS.

An important calculation on capacity is done by the PGC entity in this model. An active event is set to monitor total electricity demand from the residential, industrial and commercial sectors monthly. If the current installed capacity is unable to meet the current RE or FF demand, the PGC builds either new RE or FF capacity. We assume any additional fossil fuel capacity built will be natural gas. The decision of what type of capacity to build up depends on both current installed capacity and current building costs. Current installed capacity is taken from the AEO's electric power sector's forecasts of electricity generating capacity. Beginning with the year 2007, the document outlines the total capacity as well as cumulative planned additions and planned retirements with forecasts up until 2030. This data was therefore used as the baseline capacity in the model. Overall capacity factor was calculated as the total output from the generation facilities (in $\mathrm{kWh}$ ) divided by total capacity over the course of an entire year (8760 hours) and is 0.582157 for the duration of the simulation.

When the electricity demand exceeds the electricity produced by the current generation capacity, the PGC will build new capacity. Since the PGC is also a profit-making entity, they will focus on minimizing potential costs. Therefore, if additional RE capacity is demanded the power entity will compare PV and wind and select the most viable option. In order for the PGC to appropriately evaluate their options, it will need to assess the projected cash flows of each installation over the average life of the equipment. To do so, the program continuously calculates the net present value of an investment of one kilowatt of each renewable energy source. This calculation includes the expected cash flow from each project-both the capital cost and fixed operation and maintenance costs as projected and documented in the Annual Energy Outlook-and a given discount rate. To keep the model widely applicable, the discount rate is established as a parameter that can be set to fit the goals of the user. The model uses the same discount rate as assumed by the Annual Energy Outlook-15\%.

\section{Results}

We analyze the installation of RE-based electricity capacity power in the presence of a tax on carbon dioxide emissions. The power generators are treated as the major point source of carbon dioxide emissions and any fines or taxes on carbon output are levied at that level. However, it is assumed that all taxes levied on the PGC entity are fully passed through to the consumers and are reflected in increased electricity prices. Monte Carlo simulations are run on multiples of \$5 in the range \$5 - \$25 per metric ton of carbon dioxide emitted, as a proper carbon tax range suggested by Parry and Pizer [13]. The basic effect of this tax is that it shifts the transition towards cleaner fuels forward as it adds to the cost of the fossil fuels, essentially incentivizing the purchasing of renewable energy. However, this has no effect on the exogenously defined percentage of the population who is installing their own rooftop PV systems and they continue installing PV in accordance with their RE preference. Therefore, the residential RE market continues to grow very similarly to the BAU case for all levels of carbon taxation (Figure 4). In raising the fossil fuel end-use price, the carbon tax makes the usage of RE more financially viable. Therefore, as can be seen in Figure 5, the tax of just \$5 per metric ton of carbon emitted actually encourages electricity consumers to begin purchasing RE from the RE power 3 full years earlier than in the base case.

In the year 2030, renewable power capacity deviates from the baseline growth again to reach over 90,000,000 $\mathrm{kW}$ as the commercial entity switches to renewable energy. As the tax level increases, the time it takes for renewable energy to reach parity with fossil fuel decreases. As a result of this shift, wind energy is build up in 


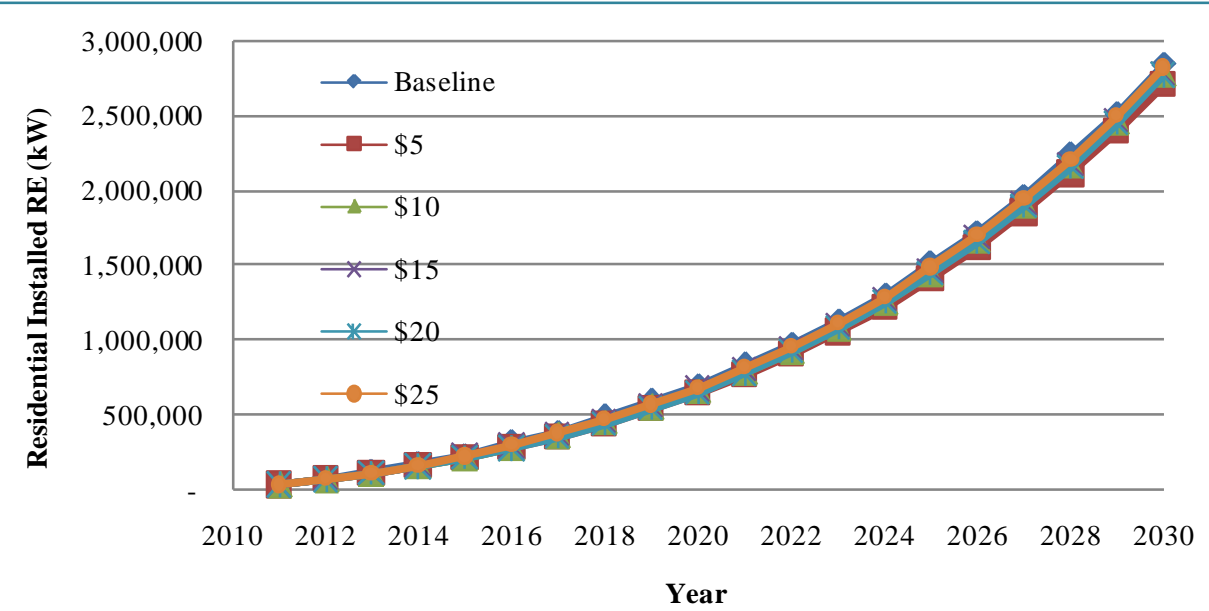

Figure 4. Residential PV projections at varying tax levels.

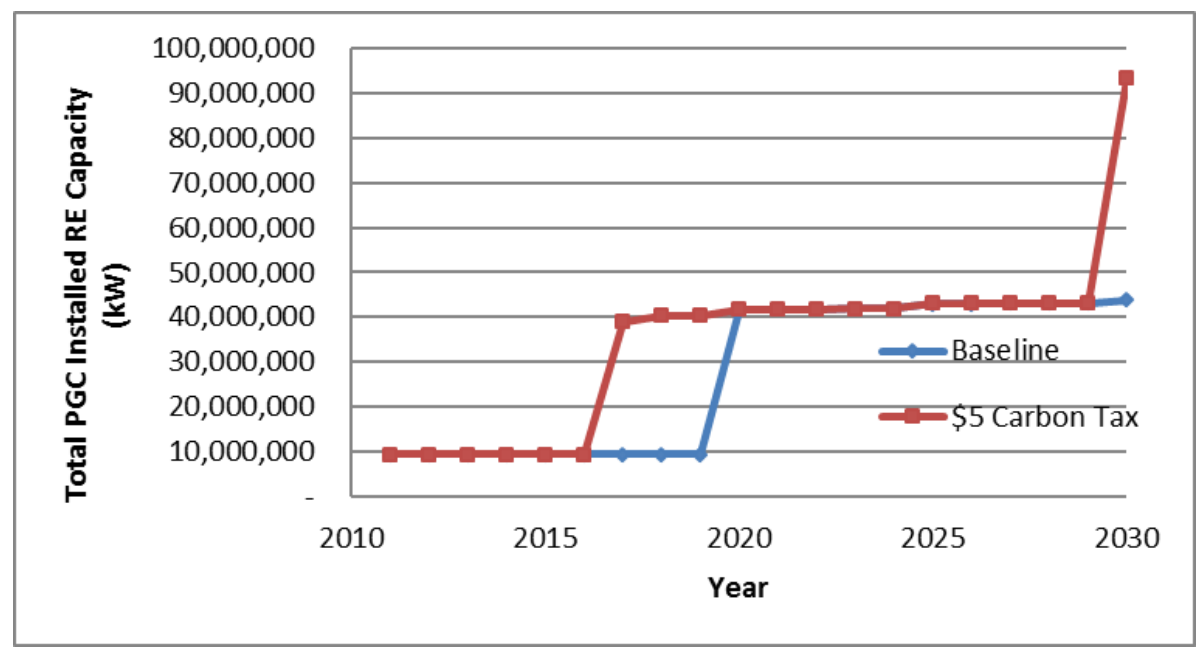

Figure 5. Installed RE capacity for the base case and the case with $\$ 5$ carbon tax.

large quantities to meet the growing demand earlier for each increase in Figure 6 and residential demand shifts fully to RE quicker with each tax raise. The tax shifts demand away from fossil fuel and towards the cheapest alternative and so, with PV being more expensive than the relatively mature technology of wind, the installed PV capacity is unaffected by the varying carbon tax levels (Figure 7).

A benefit of the quicker shift away from fossil fuels is that more carbon is abated than in the baseline scenario (Figure 8). The demand for clean energy grows as the carbon tax adds to the cost of fossil fuel energy and wind energy is utilized at earlier years as the carbon tax increases. As this happens, fossil fuel plants are used to meet less demand and emit less carbon overall. The end result is that for each additional dollar of carbon tax, more carbon is abated. This test can also be used to generate an updated renewable portfolio standard for scenarios under various carbon tax regimes. The RPS enumerates installed capacity milestones for renewable energy in Texas. By changing the fossil fuel price, the carbon tax affects the renewable energy technology adoption rate and therefore, if implemented, would lead to different expected values for the installed capacities of renewable energy technology over time. Utilizing the cumulative distribution functions of the probability distributions resulting from the Monte Carlo simulations on total installed RE capacity, Table 1 summarizes RPS confidence levels for a carbon tax. First, it can be seen that in the level of the tax affects the speed at which the RE capacity is built up, but that they all induce roughly the same amount of buildup at the end of the 20 year simulation. Increasing carbon taxes lessen the price difference between $\mathrm{FF}$ and RE options earlier and therefore it can be seen that taxes of \$ 5 and \$ 10 do not have as an immediate effect has higher taxes which encourage buildup starting in 2015. However, as was evident in Figure 6, all taxes lower the price enough to encourage the commercial 


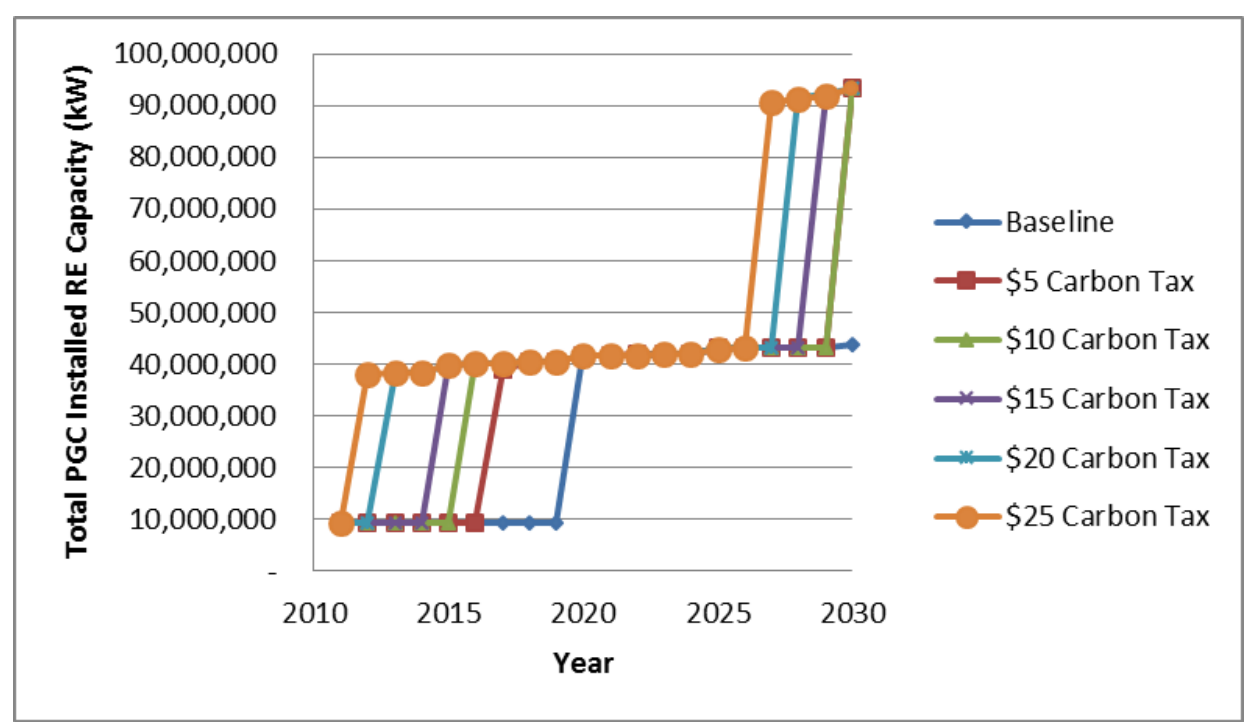

Figure 6. Installed RE capacity for varying levels of carbon tax.

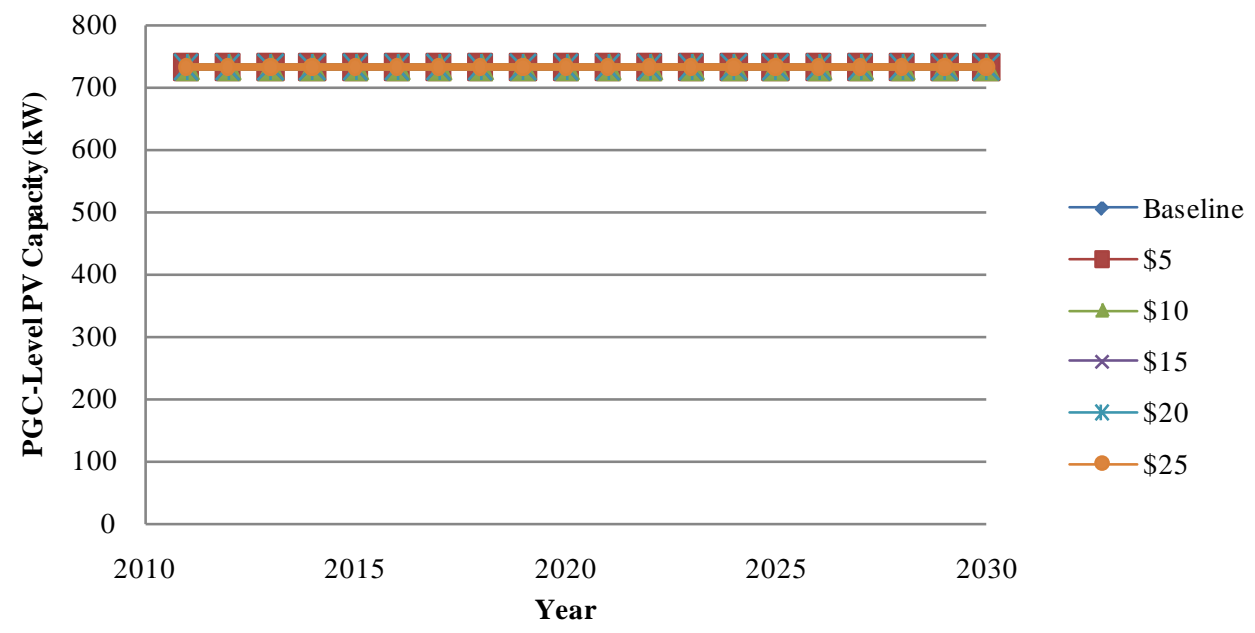

Figure 7. PV installed at varying carbon tax levels.

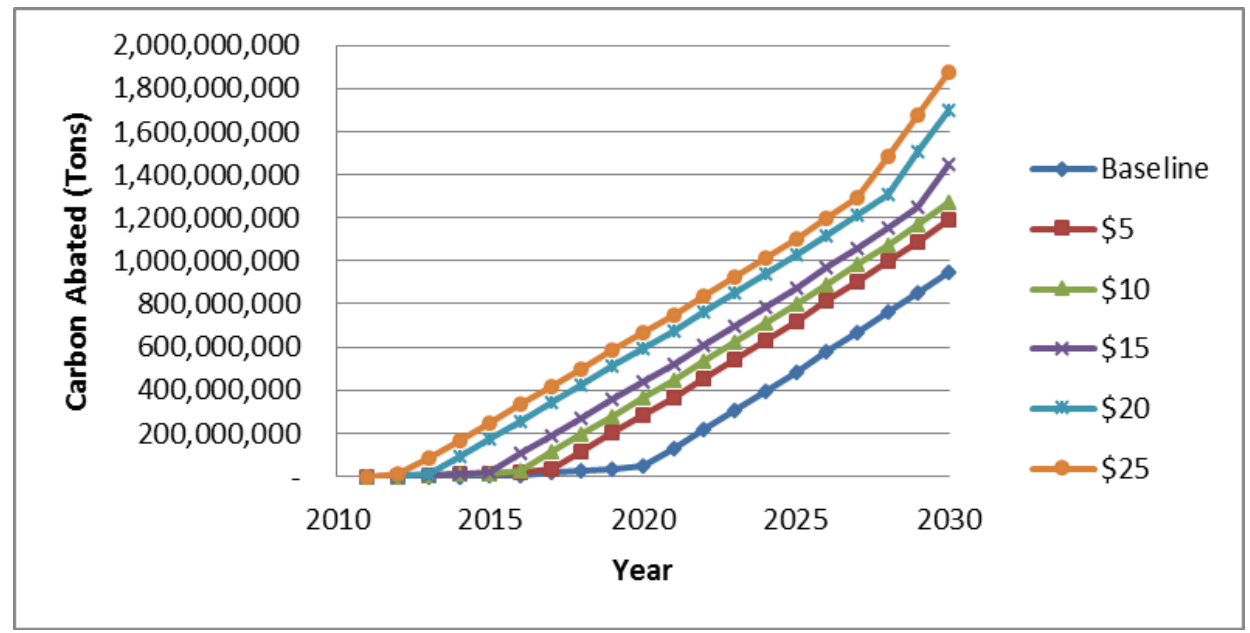

Figure 8. Carbon abated at varying carbon tax levels. 
Table 1. Proposed updated RPS under various carbon tax regimes (kW RE installed).

\begin{tabular}{|c|c|c|c|c|c|c|}
\hline & & \multicolumn{5}{|c|}{ Likelihood Level of RPS Target } \\
\hline & & $95 \%$ & $75 \%$ & $50 \%$ & $25 \%$ & $5 \%$ \\
\hline \multirow{4}{*}{ \$5 Carbon Tax } & 2015 & $9,404,100$ & $9,404,100$ & $9,404,100$ & $9,404,100$ & $9,404,100$ \\
\hline & 2020 & $41,229,630$ & $41,577,390$ & $41,698,941$ & $41,886,806$ & $42,027,630$ \\
\hline & 2025 & $42,126,230$ & $42,780,230$ & $43,054,954$ & $43,412,430$ & $43,712,180$ \\
\hline & 2030 & $91,742,530$ & $92,930,530$ & $93,432,299$ & $94,056,004$ & $94,622,530$ \\
\hline \multirow{4}{*}{$\$ 10$ Carbon Tax } & 2015 & $9,404,100$ & $9,404,100$ & $9,404,100$ & $9,404,100$ & $9,404,100$ \\
\hline & 2020 & $41,163,330$ & $41,568,992$ & $41,686,366$ & $41,874,035$ & $42,022,759$ \\
\hline & 2025 & $42,022,630$ & $42,778,630$ & $43,025,218$ & $43,366,630$ & $43,702,630$ \\
\hline & 2030 & $91,643,830$ & $92,917,287$ & $93,384,134$ & $93,940,163$ & $94,568,750$ \\
\hline \multirow{4}{*}{ \$15 Carbon Tax } & 2015 & $39,725,520$ & $39,863,029$ & $39,928,664$ & $40,005,429$ & $40,078,800$ \\
\hline & 2020 & $41,171,800$ & $41,506,200$ & $41,677,515$ & $41,875,800$ & $42,031,267$ \\
\hline & 2025 & $42,076,220$ & $42,687,740$ & $43,014,298$ & $43,409,084$ & $43,723,580$ \\
\hline & 2030 & $91,763,000$ & $92,791,500$ & $93,383,390$ & $94,043,000$ & $94,601,000$ \\
\hline \multirow{4}{*}{$\$ 20$ Carbon Tax } & 2015 & $39,736,363$ & $39,879,401$ & $39,932,335$ & $40,009,030$ & $40,065,373$ \\
\hline & 2020 & $41,230,630$ & $41,555,630$ & $41,698,007$ & $41,884,630$ & $42,032,630$ \\
\hline & 2025 & $42,107,030$ & $42,771,487$ & $43,028,557$ & $43,380,452$ & $43,710,630$ \\
\hline & 2030 & $91,826,130$ & $92,929,063$ & $93,390,895$ & $94,009,142$ & $94,533,330$ \\
\hline \multirow{4}{*}{ \$25 Carbon Tax } & 2015 & $39,714,730$ & $39,858,730$ & $39,925,411$ & $40,008,597$ & $40,079,530$ \\
\hline & 2020 & $41,165,650$ & $41,517,430$ & $41,670,504$ & $41,876,530$ & $42,027,871$ \\
\hline & 2025 & $42,057,330$ & $42,682,930$ & $42,998,018$ & $43,381,330$ & $43,687,238$ \\
\hline & 2030 & $91,748,430$ & $92,801,763$ & $93,351,871$ & $93,984,620$ & $94,548,430$ \\
\hline
\end{tabular}

entity to switch at different times throughout the simulation the end result of which is that by 2030, in each case the installed capacity is increased to meet the substantially increased demand.

Since each tax has roughly the same end result, an important policy implication is that if the government is interested in implementing a tax on carbon emitted, the level doesn't necessarily affect the long-term RE capacity in concrete terms but affects the speed at which excess capacity is built up, thereby affecting the carbon abatement activity. Therefore, depending upon the goal of the carbon tax (be it to increase RE capacity or to curb carbon emissions), the government can set the taxation level differently. If the goal is abate the most carbon, the government should set a higher tax amount regardless of the political pressure against it. Conversely, if the goal is to simply achieve high RE capacity levels, then it may behoove a legislative authority to take the advice of Parry and Pizer [13] and set the tax so that it simply covers the administrative costs-possibly decreasing the opposition to the tax.

\section{Conclusions and Discussions}

This paper developed a model to analyze the renewable energy potential in the deregulated Texas electricity market when a carbon tax is introduced. Utilizing data on consumer behavior, this research suggests that the combination of agent-based modeling and decision tree analysis can be a very useful tool for analyzing the future of the deregulated energy market. One problem with the initial goals outlined in the renewable portfolio schedules enumerated in SB7 and SB20 were that they were too conservative. Future iterations of the RPS need to be more liberal and consistent with stated goals. If a given policy instrument will lead to much more installed 
RE capacity than the published RPS, the state energy legislation will appear ineffectual and will lack credibility in the future.

In fact the evaluation of risk is a major factor that will impact the success of renewable energy over the long and short term. If legislators can include in their policies caps which would limit the liabilities of power producers, the producers themselves would be more willing to take risks and install larger amounts of RE. Any sort of legal safety net would undoubtedly add to the costs of RE, but could be justified by the expected increase in RE technological diffusion. Similarly, one way to ensure that policy hedges its risks is by encouraging the diversification of renewable energy technology. A positive aspect of the SB20 RPS update was that it added an element of variety to the technology of choice (wind) through provisions that $500 \mathrm{MW}$ of capacity be provided by solar energy by 2025. Similar to wind, this target has already been surpassed, but the aim was well-intentioned and just too conservative.

\section{References}

[1] Public Utility Commission of Texas (2011) Power to Choose. Texas Electric Choice Education Program.

[2] Calais, C. (2009) Politics 101: What Is Texas Renewable Portfolio Standard? Dallas Examiner.

[3] (2010) Public Utility Commission of Texas. Direct Energy Contact US.

[4] (2010) Texas Electricity Restructuring Active. U.S. Energy Information Administration.

[5] Texas Renewable Portfolio Standard. Texas State Energy Conservation Office.

[6] (2009) Final Report on CM907. Center for Energy Economics: Bureau of Economic Geology, Jackson School of Geosciences, the University of Texas at Austin.

[7] (2010) Annual Energy Outlook 2010. U.S. DOE, U.S. Energy Information Administration, Washington DC.

[8] (2010) State Electricity Profiles-2008. U.S. Energy Information Administration, U.S. DOE, Washington DC, 264265.

[9] (2008) 2008 Texas Population Projections. Texas State Data Center.

[10] Bird, L., Kreycik, C. and Friedman, B. (2008) Green Power Marketing in the United States: A Status Report. 11th Edition, NREL, Golden, 49.

[11] Paidipati, J., Frantzis, L., Sawyer, H. and Kurrasch, A. (2008) Rooftop Photovoltaics Market Penetration Scenarios. National Renewable Energy Laboratory (NREL), Golden. http://dx.doi.org/10.2172/924645

[12] (2010) State Electricity Profiles-2008. U.S. DOE, U.S. Energy Information Administration, Washington DC, 264265.

[13] Parry, I.W.H. and Pizer, W.A. (2007) Combating Global Warming. Regulation, 30. 